\title{
Aiming for a negative fluid balance in patients with acute lung injury and increased intra- abdominal pressure: a pilot study looking at the effects of PAL-treatment
}

\author{
Colin Cordemans ${ }^{1}$, Inneke De laet ${ }^{1}$, Niels Van Regenmortel ${ }^{1}$, Karen Schoonheydt ${ }^{1}$, Hilde Dits, Greg Martin², \\ Wolfgang Huber ${ }^{3}$, Manu LNG Malbrain ${ }^{1 *}$
}

\begin{abstract}
Introduction: Achievement of a negative fluid balance in patients with capillary leak is associated with improved outcome. We investigated the effects of a multi-modal restrictive fluid strategy aiming for negative fluid balance in patients with acute lung injury (ALI).

Methods: In this retrospective matched case-control study, we included 114 mechanically ventilated (MV) patients with ALI. We compared outcomes between a group of 57 patients receiving PAL-treatment (PAL group) and a matched control group, abstracted from a historical cohort. PAL-treatment combines high levels of positive end-expiratory pressure, small volume resuscitation with hyperoncotic albumin, and fluid removal with furosemide (Lasix ${ }^{\circledR}$ ) or ultrafiltration. Effects on extravascular lung water index (EVLWI), intra-abdominal pressure (IAP), organ function, and vasopressor therapy were recorded during 1 week. The primary outcome parameter was 28-day mortality.

Results: At baseline, no significant intergroup differences were found, except for lower $\mathrm{PaO}_{2} / \mathrm{FIO}_{2}$ and increased IAP in the PAL group (174.5 \pm 84.5 vs $256.5 \pm 152.7, p=0.001 ; 10.0 \pm 4.2$ vs $8.0 \pm 3.7 \mathrm{mmHg}, p=0.013$, respectively). After 1 week, PAL-treated patients had a greater reduction of EVLWI, IAP, and cumulative fluid balance $(-4.2 \pm 5.6 \mathrm{vs}-1.1 \pm$ $3.7 \mathrm{~mL} / \mathrm{kg}, p=0.006 ;-0.4 \pm 3.6$ vs $1.8 \pm 3.8 \mathrm{mmHg}, p=0.007 ;-1,451 \pm 7,761$ vs $8,027 \pm 5,254 \mathrm{~mL}, p<0.001)$.

Repercussions on cardiovascular and renal function were limited. PAL-treated patients required fewer days of intensive care unit admission and days on MV (23.6 \pm 15 vs $37.1 \pm 19.9$ days, $p=0.006 ; 14.6 \pm 10.7$ vs $25.5 \pm 20.2$ days, respectively) and had a lower 28 -day mortality ( $28.1 \%$ vs $49.1 \%, p=0.034)$.
\end{abstract}

Conclusion: PAL-treatment in patients with ALI is associated with a negative fluid balance, a reduction of EVLWI and IAP, and improved clinical outcomes without compromising organ function.

\section{Introduction}

Both early and late fluid management affect outcome in acute lung injury (ALI), sepsis, and trauma [1-5]. After initial filling to reverse distributive shock [6], emphasis shifts to limitation and elimination of interstitial edema in vital organs. Indeed, a positive fluid balance resulting from third spacing is independently associated with impaired organ function and worse outcome [7-11].

\footnotetext{
* Correspondence: manu.malbrain@skynet.be

'Department of Intensive Care, Ziekenhuis Netwerk Antwerpen, ZNA Stuivenberg, Campus Stuivenberg, Lange Beeldekensstraat 267, 2060, Antwerpen 6, Belgium

Full list of author information is available at the end of the article
}

Conversely, achievement of negative fluid balances predicts survival and improves lung function [12,13].

Bedside measurement of extravascular lung water index (EVLWI) performed by transpulmonary thermodilution allows to estimate the extent of capillary leak and fluid overload [14-17]. Accordingly, EVLWI correlates well with organ function and survival $[15,16,18,19]$. Moreover, fluid management aimed at EVLWI reduction results in a more negative fluid balance and improved outcomes [20]. In order to achieve a negative fluid balance, previous prospective trials excluded patients with hypotension and renal failure [12,20,21].

\section{SpringerOpen ${ }^{\circ}$}

(C) 2012 Cordemans et al.; licensee Springer This is an open access article distributed under the terms of the Creative Commons Attribution License (http://creativecommons.org/licenses/by/2.0), which permits unrestricted use, distribution, and reproduction in any medium, provided the original work is properly cited. 
In this study, we aimed for a negative fluid balance in mechanically ventilated patients with ALI presenting with severe hypoxemia, increased EVLWI, and intraabdominal pressure (IAP) using a restrictive fluid management, referred to in our institution as "PAL-treatment". PAL-treatment combines high levels of positive end-expiratory pressure (PEEP), small volume resuscitation with hyperoncotic albumin, and fluid removal with furosemide $\left(\right.$ Lasix $^{\circledR}$ ) or ultrafiltration during continuous renal replacement therapy (CRRT).

\section{Methods}

\section{Study design}

In this retrospective matched case-control single center study, patients with PAL-treatment were compared to a matched control group for 1 week from the onset of ALI. Outcomes were assessed at day 28 after enrolment or at the day of death or hospital discharge, whichever occurred first. The primary outcome parameter was hospital mortality. Secondary outcomes included intensive care unit (ICU) and hospital length of stay, development of intraabdominal hypertension (IAH), duration of mechanical ventilation (MV) and cumulative fluid balance, organ dysfunction, and vasopressor therapy requirements after 1 week.

\section{Patients}

Data of 114 patients treated in two ICU's in Ziekenhuis Netwerk Antwerpen, ZNA Campus Stuivenberg, Antwerp, Belgium were collected from March 2004 to August 2007 (control group) and from March 2008 to February 2010 (PAL group). Patients were consecutively included if they were intubated and MV and if monitoring with transpulmonary thermodilution technique was performed.

The PAL group consisted of 57 patients with ALI according to international criteria [22], in whom a negative daily fluid balance was deemed necessary, according to clinical appraisal of low $\mathrm{P}_{\mathrm{a}} \mathrm{O}_{2} / \mathrm{FIO}_{2}$ ratio and increased EVLWI and IAP. All patients were included at the onset of ALI.

The historical cohort consisted of $123 \mathrm{MV}$ patients with thermodilution catheter monitoring, of which 65 patients met the criteria of ALI [22] and had data available from the onset of ALI. We used an automatic case-control matching software module to abstract 57 control patients from this group. In this way, controls were matched to PAL-treated patients with regard to demographics, etiology of lung injury, severity of illness, organ dysfunction, fluid balance, and EVLWI at baseline.

\section{Treatment protocol}

Approval for this epidemiologic study was granted by our institutional review board (EC approval number 3766). Due to the observational and retrospective character of this study, informed consent was waived. Standard treatment was based on recent ICU guidelines and did not differ between the two groups.

Patients in the PAL group received a combination therapy aiming for negative daily fluid balances. First, application of PEEP was titrated to counterbalance increased IAP (best PEEP in $\mathrm{cmH}_{2} \mathrm{O}=$ IAP in $\mathrm{mmHg}$ ). Next, hyperoncotic albumin (20\%) solution was administered by $200-\mathrm{ml}$ boluses over $60 \mathrm{~min}$ twice on the first day and subsequently titrated toward a serum albumin level of $30 \mathrm{~g} / \mathrm{L}$. Finally, a furosemide drip was initiated with an intravenous loading dose of $60 \mathrm{mg}$, followed by a continuous infusion at $60 \mathrm{mg} / \mathrm{h}$ for the first $4 \mathrm{~h}$ and $5-10 \mathrm{mg} / \mathrm{h}$ thereafter, according to hemodynamic tolerance. In anuric patients, CRRT was initiated with an ultrafiltration rate resulting in neutral to negative daily fluid balances.

\section{Data collection}

Demographic, clinical, and laboratory data were registered in an electronic database, supplemented with daily fluid balance, sepsis-related organ failure assessment (SOFA) score, IAP, MV settings, and hemodynamic variables. Finally, data on total duration of MV, CRRT, ICU stay, hospital stay, and mortality on day 28 were added to the database.

Capillary leak index (CLI) was defined as C-reactive protein (CRP; milligrams per deciliter) over albumin (grams per liter) ratio, multiplied by 100 [23]. Requirement of vasopressor therapy was determined by the need of norepinephrine with a dose $\geq 0.1 \mu \mathrm{g} / \mathrm{kg} / \mathrm{min}$.

Severity of illness on ICU admission was described by an averaged simplified acute physiology (SAPS II) score [24], acute physiology and chronic health evaluation (APACHE II) score [25], and SOFA score [26]. Daily fluid balance was calculated by subtracting the fluid output (diuresis, ultrafiltration volume in case of CRRT, and any loss from drainage tubes) from the fluid intake (IV and enteral fluid administration); each day the cumulative fluid balance was computed by the addition of daily fluid balances.

IAP was the mean of two daily IAP measurements via a Foley bladder catheter, as described previously [27]. $\mathrm{IAH}$ was defined as persistent increase of IAP $\geq 12$ $\mathrm{mmHg}$ and abdominal perfusion pressure (APP) as mean arterial pressure (MAP) minus IAP according to consensus definitions [8].

A central venous catheter and a thermistor-tipped arterial thermodilution catheter (Pulsiocath 5F) inserted into the femoral artery and attached to a PiCCOplus ${ }^{\circledR}$ system (Pulsion Medical Systems, Munich, Germany) were already in place for each patient. Transpulmonary thermodilution measurements were obtained by central venous injection of three $20-\mathrm{mL}$ boluses of cooled saline 
$\left(<8^{\circ} \mathrm{C}\right)$. For each set of thermodilution determinations, the mean values were used for statistical analysis. Cardiac output (CO), global end diastolic volume (GEDV), extravascular lung water (EVLW), global ejection fraction (GEF), pulmonary vascular permeability index, stroke volume variation (SVV), and pulse pressure variation were calculated using the PiCCOplus ${ }^{\circledR}$ [17]. EVLW was indexed to body weight (EVLWI) and $\mathrm{CO}$ and GEDV to body surface area (cardiac index (CI), GEDVI).

\section{Statistical analysis}

A priori analyses were performed to stratify patient groups by demographics, etiology of lung injury, severity of illness, organ dysfunction, fluid balance, and EVLWI at baseline. We analyzed data on intent-to-treat basis comparing outcomes on different time points within groups and between groups during 1 week.

Continuous data were expressed by mean \pm standard deviation (SD), and intergroup differences were determined by one-way analysis of variance (ANOVA) analyses day by day for 1 week (univariate analysis). Categorical data were expressed as frequency distributions and/or percentages, and the $\chi^{2}$ test was used to determine intergroup differences. Two-sided $p$ values of 0.05 or less were considered to indicate statistical significance.

Time course of PEEP, albumin, $\mathrm{P}_{\mathrm{a}} \mathrm{O}_{2} / \mathrm{FIO}_{2}$ ratio, EVLWI, daily and cumulative fluid balance, SOFA score, and IAP was described by clustered error bar graphs representing mean \pm standard error. The Kaplan-Meier method was used to analyze differences in cumulative survival and duration of mechanical ventilation. We used SPSS software package (version 17.0.1; SPSS, Chicago, IL, USA). Automatic case-control matching was performed with the fuzzy extension (http://www.spss. com/devcentral).

\section{Results}

\section{Baseline characteristics}

We included 114 mainly medical $(n=102)$ mechanically ventilated patients with ALI. Fifty-five patients (48.2\%) required vasopressor therapy, and 50 patients (43.9\%) received CRRT at baseline.

The PAL group had on average lower $\mathrm{PaO}_{2} / \mathrm{FIO}_{2}$ (higher respiratory SOFA score), increased IAP, and higher PEEP level. Otherwise, the two groups were similar (Table 1).

\section{Direct treatment effects (Figure 1 and Table 2)}

Serum albumin concentration averaged $26.0 \pm 7.4 \mathrm{~g} / \mathrm{L}$ in the total group. From day 2, patients in the PAL group had significantly higher concentrations, rising to $33.0 \pm$ $7.3 \mathrm{~g} / \mathrm{L}$ on day $7(p<0.001)$. Controls had no significant increase in albumin after 1 week $(25.3 \pm 8.0$ vs $26.4 \pm$ $5.0 \mathrm{~g} / \mathrm{L}, p=0.399)$.
CLI was significantly reduced during 1 week of PALtreatment $(62.9 \pm 48.4$ vs $31.9 \pm 25.5, p<0.001)$, in contrast to non-significant reductions in the control group $(68.9 \pm 66.3$ vs $51.8 \pm 42.5, p=0.139)$.

In the PAL group, average PEEP for the entire week was significantly higher $\left(11.0 \pm 2.8\right.$ vs $7.9 \pm 2.9 \mathrm{cmH}_{2} \mathrm{O}$, $p<0.001)$ compared to controls. PEEP level correlated with average IAP of $10.0 \pm 3.4 \mathrm{mmHg}(R=0.293, p<$ 0.001).

After the day of enrolment, patients in the PAL group had significantly lower daily fluid balances on each day; a negative daily fluid balance was achieved on average by day 4 . PAL-treated patients had a trend toward higher average urine output $(1,844 \pm 1,714$ vs $1,681 \pm$ $1,635 \mathrm{~mL}, p=0.182$ ). Resulting cumulative fluid balance after 1 week was significantly higher in the control group.

\section{Effects on organ function (Figure 2 and Table 2)}

Respiratory function improved significantly in the PAL group. The $\mathrm{PaO}_{2} / \mathrm{FIO}_{2}$ ratio increased from $174.5 \pm 84.5$ to $274.4 \pm 116.9(p<0.001)$ after 1 week in PAL-treated patients but remained unchanged in the control group $(256.6 \pm 152.7$ vs $244.2 \pm 98.3, p=0.641)$. Accordingly, respiratory SOFA score after 1 week decreased only in the PAL group. EVLWI was reduced from $12.0 \pm 6.1$ to $10.9 \pm$ $3.2 \mathrm{~mL} / \mathrm{kg}(p=0.021)$ in the control group and from 13.4 \pm 6.2 to $9.2 \pm 3.6 \mathrm{~mL} / \mathrm{kg}(p=0.006)$ in the PAL group. Except for a higher setting of PEEP, respiratory mechanics were similar between groups at all time points.

Overall hemodynamic impact assessed with cardiovascular SOFA score shows a significant improvement after 1 week in the PAL group $(3.0 \pm 1.2$ vs $1.8 \pm 1.6, p<$ 0.001 ) and a modest but insignificant decrease in the control group $(2.9 \pm 1.5$ vs $2.4 \pm 1.5, p=0.099)$. Time course of the MAP/heart rate ratio is shown in Figure 2. Other hemodynamic monitoring variables were not significantly affected.

After 1 week, a higher percentage of patients required vasopressor therapy in the PAL group (Table 3 ). Furthermore, average dose of norepinephrine for the entire week was greater in the PAL group (0.281 \pm 0.284 vs $0.180 \pm 0.129 \mu \mathrm{g} / \mathrm{kg} / \mathrm{min}, p=0.005$ ).

Changes in renal function as assessed with renal SOFA score were similar in both groups. However, average serum creatinine during the observed week was higher in PAL-treated patients $(1.9 \pm 3.3$ vs $1.6 \pm 1.3$ $\mathrm{mg} / \mathrm{dL}, p=0.038$ ) (Table 2).

As shown in Table 2 and Figure 3, IAP increased in the control group but remained stable in the PAL group. The APP remained unchanged during the whole week. During observation, $33.6 \%$ of patients developed IAH, $39.6 \%$ in the PAL group, and $27.8 \%$ in the control group $(p=0.224)$. 
Table 1 Baseline characteristics

\begin{tabular}{|c|c|c|c|}
\hline Variable & Control group $(n=57)$ & PAL group $(n=57)$ & $p$ value \\
\hline Age (year) & $61.4 \pm 16.8$ & $63.0 \pm 14.3$ & 0.598 \\
\hline Male sex (\%) & 73.7 & 66.7 & 0.539 \\
\hline BMl & $25.2 \pm 4.0$ & $26.1 \pm 6.0$ & 0.366 \\
\hline Primary lung injury (\%) & & & 0.607 \\
\hline Sepsis & 43.9 & 47.4 & \\
\hline Pneumonia & 22.8 & 26.3 & \\
\hline Aspiration & 12.3 & 8.8 & \\
\hline Burns & 5.3 & 7.0 & \\
\hline Trauma & 7.0 & 3.5 & \\
\hline Other & 8.8 & 7.0 & \\
\hline Medical ICU (\%) & 87.7 & 91.2 & 0.344 \\
\hline \multicolumn{4}{|l|}{ Severity of disease } \\
\hline SAPS $\|$ & $52.3 \pm 17.3$ & $47.9 \pm 18.4$ & 0.188 \\
\hline APACHE ॥ & $22.7 \pm 11.1$ & $22.9 \pm 11.4$ & 0.934 \\
\hline \multicolumn{4}{|l|}{ SOFA score } \\
\hline Respiratory & $1.9 \pm 1.4$ & $2.4 \pm 1.3$ & 0.037 \\
\hline Coagulation & $0.9 \pm 1.2$ & $1.0 \pm 1.2$ & 0.488 \\
\hline Liver & $0.6 \pm 1.0$ & $0.8 \pm 1.2$ & 0.302 \\
\hline Cardiovascular & $2.9 \pm 1.5$ & $3.0 \pm 1.2$ & 0.640 \\
\hline Nervous & $2.5 \pm 1.7$ & $2.6 \pm 1.6$ & 0.867 \\
\hline Renal & $1.5 \pm 1.6$ & $1.5 \pm 1.6$ & 0.864 \\
\hline Total & $10.2 \pm 4.2$ & $11.3 \pm 4.0$ & 0.160 \\
\hline Number of organs failing & $2.1 \pm 1.1$ & $2.5 \pm 1.2$ & 0.061 \\
\hline \multicolumn{4}{|l|}{ Hemodynamic variables } \\
\hline $\mathrm{HR}(\mathrm{bpm})$ & $98.0 \pm 18.0$ & $96.5 \pm 19.4$ & 0.733 \\
\hline Mean arterial pressure $(\mathrm{mmHg})$ & $83.3 \pm 13.5$ & $84.9 \pm 11.0$ & 0.502 \\
\hline Vasopressor use (\%) & 58.0 & 52.0 & 0.688 \\
\hline $\mathrm{Cl}\left(\mathrm{L} / \mathrm{min} / \mathrm{m}^{2}\right)$ & $3.4 \pm 0.9$ & $3.8 \pm 0.9$ & 0.145 \\
\hline SW (\%) & $15.5 \pm 8.4$ & $12.0 \pm 5.5$ & 0.088 \\
\hline GEF (\%) & $19.7 \pm 6.6$ & $22.1 \pm 7.6$ & 0.260 \\
\hline GEDVI $\left(\mathrm{mL} / \mathrm{m}^{2}\right)$ & $736.8 \pm 141.5$ & $807.5 \pm 189.3$ & 0.163 \\
\hline EVLWI $(\mathrm{mL} / \mathrm{kg})$ & $12.0 \pm 6.1$ & $13.4 \pm 6.2$ & 0.326 \\
\hline \multicolumn{4}{|l|}{ Respiratory variables } \\
\hline Tidal volume (mL/kg of PBW) & $8.6 \pm 1.8$ & $7.9 \pm 1.9$ & 0.119 \\
\hline Plateau pressure $\left(\mathrm{cmH}_{2} \mathrm{O}\right)$ & $25.1 \pm 9.1$ & $25.3 \pm 7.4$ & 0.914 \\
\hline PEEP $\left(\mathrm{cmH}_{2} \mathrm{O}\right)$ & $6.7 \pm 2.4$ & $10.2 \pm 2.9$ & $<0.001$ \\
\hline Dynamic compliance $\left(\mathrm{mL} / \mathrm{cmH}_{2} \mathrm{O}\right)$ & $39.4 \pm 17.4$ & $42.8 \pm 22.4$ & 0.402 \\
\hline $\mathrm{PaO}_{2} / \mathrm{FIO}_{2}$ & $256.5 \pm 152.7$ & $174.5 \pm 84.5$ & 0.001 \\
\hline \multicolumn{4}{|l|}{ Renal and metabolic variables } \\
\hline Creatinine $(\mathrm{mg} / \mathrm{dL})$ & $2.1 \pm 2.2$ & $1.8 \pm 1.5$ & 0.393 \\
\hline Urine output (mL/day) & $1,366 \pm 1,273$ & $1,591 \pm 1,139$ & 0.323 \\
\hline CRRT (\%) & 47.4 & 40.4 & 0.571 \\
\hline Albumin $(\mathrm{g} / \mathrm{L})$ & $25.3 \pm 8.0$ & $26.7 \pm 6.6$ & 0.297 \\
\hline $\mathrm{pH}$ & $7.33 \pm 0.12$ & $7.35 \pm 0.11$ & 0.430 \\
\hline \multicolumn{4}{|l|}{ Immune system } \\
\hline CRP $(\mathrm{mg} / \mathrm{dL})$ & $14.7 \pm 13.5$ & $15.3 \pm 10.1$ & 0.806 \\
\hline \multicolumn{4}{|l|}{ Central nervous system } \\
\hline Glasgow Coma Score & $8.2 \pm 5.4$ & $7.6 \pm 5.1$ & 0.557 \\
\hline Capillary leak index & $68.9 \pm 66.3$ & $62.9 \pm 48.4$ & 0.589 \\
\hline Intra-abdominal pressure (mmHg) & $8.0 \pm 3.7$ & $10.0 \pm 4.2$ & 0.013 \\
\hline
\end{tabular}


Table 1 Baseline characteristics (Continued)

\begin{tabular}{|c|c|c|c|}
\hline Abdominal perfusion pressure (mmHg) & $75.3 \pm 14.0$ & $75.1 \pm 12.9$ & 0.933 \\
\hline Fluid balance day before enrolment $(\mathrm{mL})$ & $2,504 \pm 2,704$ & $1,659 \pm 4,419$ & 0.224 \\
\hline
\end{tabular}

\section{Major outcomes (Table 3 and Figure 4)}

A total of 44 patients (38.6\%) died, with more deaths in the control group than in the PAL group (49.1 vs $28.1 \%, p$ $=0.034)$. Patients in the PAL group surviving their ICU stay required fewer days of ICU admission and days on MV. Total hospital stay and days with CRRT were similar in both groups.

\section{Discussion}

In this study, we demonstrated that a multi-modal approach using PAL-treatment in patients with ALI achieves negative cumulative fluid balance without compromising organ function. Furthermore, compared to a matched control group, we found improved oxygenation, EVLWI and IAP reduction, fewer days on mechanical
PANEL A: PEEP

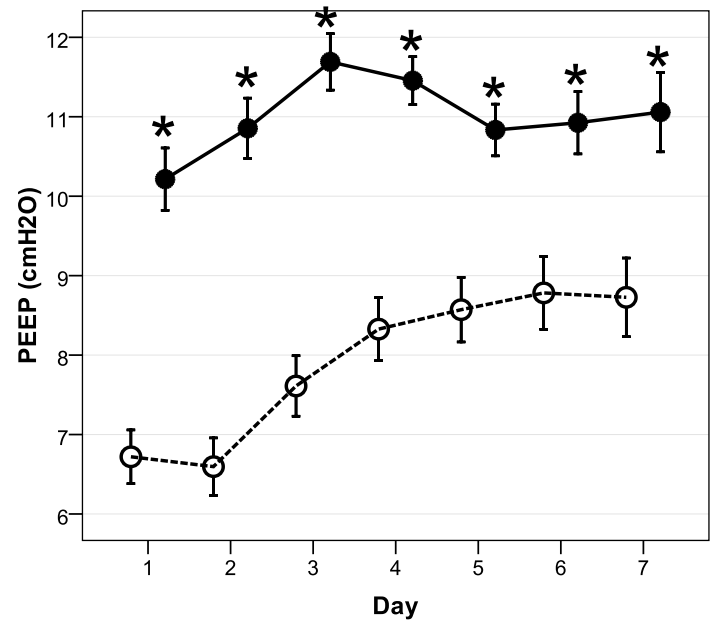

PANEL C: Daily Fluid Balance

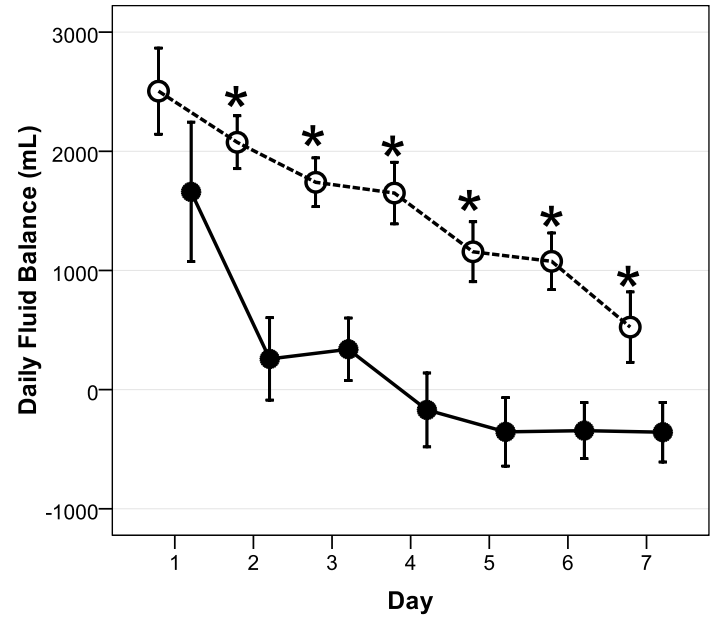

PANEL B: serum albumin

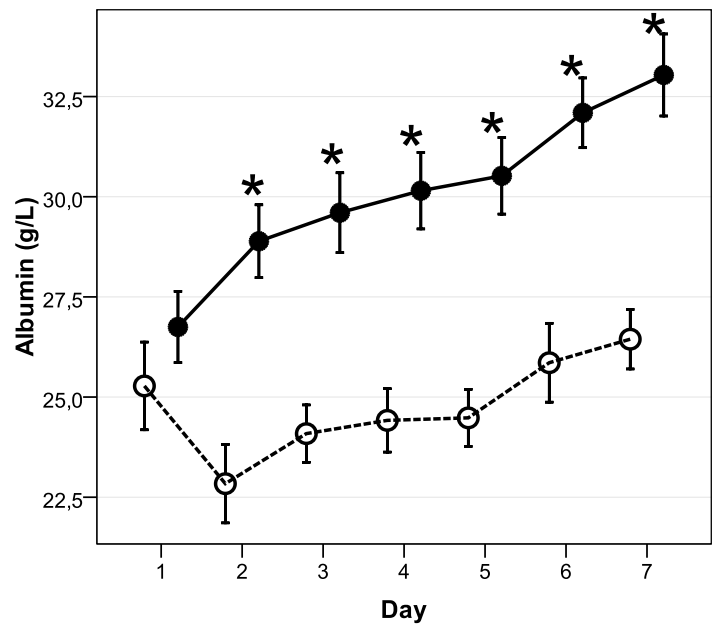

PANEL D: Cumulative Fluid Balance

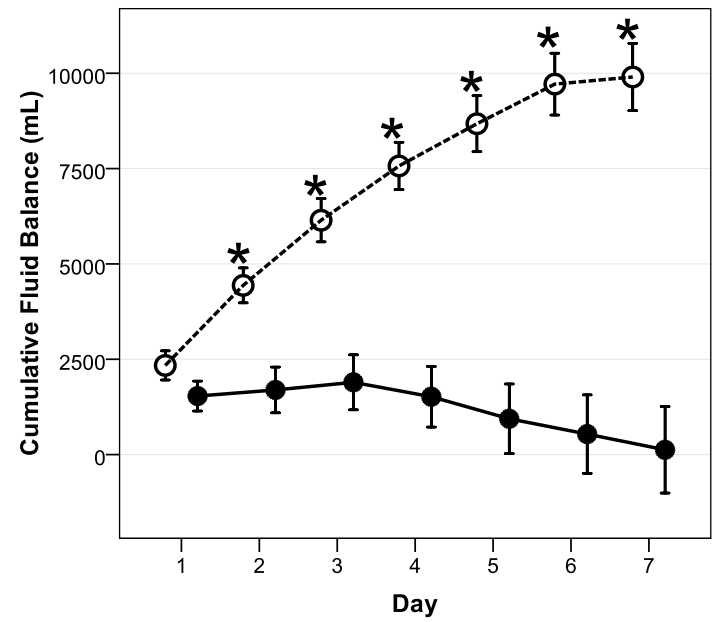

Figure 1 Mean \pm standard error of variables directly affected by 1 week of PAL-treatment. PAL-treated patients are depicted by a full line and control patients by a dotted line. ${ }^{*} p<0.05$, day-by-day pairwise compared between the PAL group and the control group (one-way ANOVA). 
Table 2 Mean absolute change of selected variables after 1 week

\begin{tabular}{|c|c|c|c|}
\hline Variable & Control group & PAL group & $p$ value \\
\hline \multicolumn{4}{|l|}{ SOFA score } \\
\hline Respiratory & $0.0 \pm 1.7$ & $-0.8 \pm 1.6$ & 0.015 \\
\hline Coagulation & $0.4 \pm 1.1$ & $0.1 \pm 0.9$ & 0.181 \\
\hline Liver & $0.3 \pm 1.1$ & $0.4 \pm 0.8$ & 0.553 \\
\hline Cardiovascular & $-0.5 \pm 1.9$ & $-1.2 \pm 2.0$ & 0.087 \\
\hline Nervous & $0.2 \pm 2.0$ & $-0.2 \pm 1.8$ & 0.271 \\
\hline Renal & $0.2 \pm 1.8$ & $0.3 \pm 1.5$ & 0.693 \\
\hline Total & $0.7 \pm 5.4$ & $-1.3 \pm 5.0$ & 0.057 \\
\hline Number of organs failing & $-0.1 \pm 1.6$ & $-0.6 \pm 1.5$ & 0.115 \\
\hline \multicolumn{4}{|l|}{ Hemodynamic variables } \\
\hline HR (bpm) & $-11.5 \pm 16.3$ & $11.1 \pm 95.2$ & 0.183 \\
\hline Mean arterial pressure $(\mathrm{mmHg})$ & $4.1 \pm 13.6$ & $0.6 \pm 15.5$ & 0.247 \\
\hline $\mathrm{Cl}\left(\mathrm{L} / \mathrm{min} / \mathrm{m}^{2}\right)$ & $0.9 \pm 0.2$ & $1.0 \pm 0.2$ & 0.274 \\
\hline \multicolumn{4}{|l|}{ Respiratory variables } \\
\hline Plateau pressure $\left(\mathrm{cmH}_{2} \mathrm{O}\right)$ & $2.2 \pm 8.6$ & $0.7 \pm 8.9$ & 0.431 \\
\hline PEEP $\left(\mathrm{cmH}_{2} \mathrm{O}\right)$ & $2.1 \pm 3.6$ & $0.5 \pm 3.8$ & 0.050 \\
\hline Dynamic compliance $\left(\mathrm{mL} / \mathrm{cmH}_{2} \mathrm{O}\right)$ & $1.6 \pm 24.3$ & $5.3 \pm 31.4$ & 0.548 \\
\hline $\mathrm{PaO}_{2} / \mathrm{FIO}_{2}$ ratio & $-12.3 \pm 166.4$ & $99.9 \pm 110.5$ & $<0.001$ \\
\hline EVLWI (mL/kg) & $-1.1 \pm 3.7$ & $-4.2 \pm 5.6$ & 0.006 \\
\hline Albumin $(g / L)$ & $1.1 \pm 9.0$ & $6.3 \pm 8.9$ & 0.008 \\
\hline Creatinine $(\mathrm{mg} / \mathrm{dL})$ & $-0.5 \pm 2.0$ & $-0.1 \pm 1.1$ & 0.171 \\
\hline Capillary leak index & $-17.1 \pm 75.5$ & $-31.0 \pm 47.4$ & 0.111 \\
\hline Intra-abdominal pressure $(\mathrm{mmHg})$ & $1.8 \pm 3.8$ & $-0.4 \pm 3.6$ & 0.007 \\
\hline Abdominal perfusion pressure $(\mathrm{mmHg})$ & $0.4 \pm 14.4$ & $1.3 \pm 15.5$ & 0.785 \\
\hline Cumulative fluid balance ( $\mathrm{mL} /$ day) & $8,027 \pm 5,254$ & $-1,451 \pm 7,761$ & $<0.001$ \\
\hline
\end{tabular}

SOFA, sepsis and organ failure assessment; $\mathrm{HR}$, heart rate; $\mathrm{Cl}$, cardiac index; PEEP, positive end-expiratory pressure; EVLWI, extravascular lung water.

ventilation, shorter ICU stay, and reduced 28-day mortality in the PAL group.

The idea behind PAL-treatment aiming for negative fluid balance in a setting of capillary leak is based on the recently rediscovered concept of the ebb and flow phase $[2,13,28,29]$. The ebb phase represents a distributive shock characterized by increased capillary permeability and albumin leak $[2,28,30]$. Excess interstitial fluid leads to organ dysfunction [31], including ALI, secondary IAH [8], and associated acute kidney injury [32]. Shock reversal and subsequent hemodynamic and renal recovery sets in the transition to the flow phase resulting in mobilization of excess extravascular (lung) water [2]. Previously, a neutral to negative cumulative balance $[1,7,10,13,33,34]$ and reduction of EVLWI were shown to correlate with improved survival $[15,16,18,19]$.

PAL-treatment intends to initiate the flow phase, limiting capillary leak and promoting interstitial fluid removal while ensuring organ perfusion at the same time. Therefore, it is a specific form of restrictive fluid management, combining open lung ventilation, small volume resuscitation with hyperoncotic albumin, and aggressive fluid removal.
Open lung ventilation strategy in ALI signifies application of high levels of PEEP [35] and is correlated with decreases in EVLWI [36]. Both the percentage of potentially recruitable lung and EVLWI are related to outcome $[15,16,18,19,35]$. The open lung strategy in ALI is associated with increased alveolar fluid clearance and reduced EVLWI [37-39]. In this study, PAL-treatment was initiated in patients with low oxygenation index and high EVLWI, potentially indicating a higher proportion of recruitable lung. Within the concept of the polycompartment syndrome, we set PEEP level $\left(\mathrm{cmH}_{2} \mathrm{O}\right)$ equal to IAP $(\mathrm{mmHg})$ in order to counteract IAP [40] (Figure 3).

Induction of the flow phase with PAL-treatment implies vascular refilling from the interstitium and subsequent removal of fluids from the body producing a net negative fluid balance. In this context, addition of small volume resuscitation with hyperoncotic albumin to a fluid removal regimen resulted in a greater negative fluid balance while maintaining better hemodynamic stability [21]. Moreover, restoration of colloid osmotic pressure in absence of elevated hydrostatic pressure may prevent further interstitial edema formation $[41,42]$. Accordingly, hypoproteinemia is highly predictive of 
PANEL A: P/F ratio

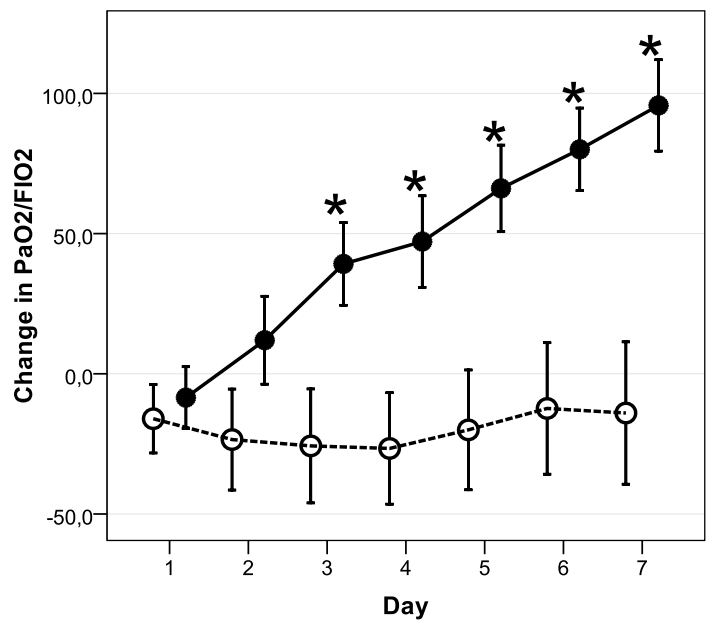

PANEL C: MAP/HR ratio

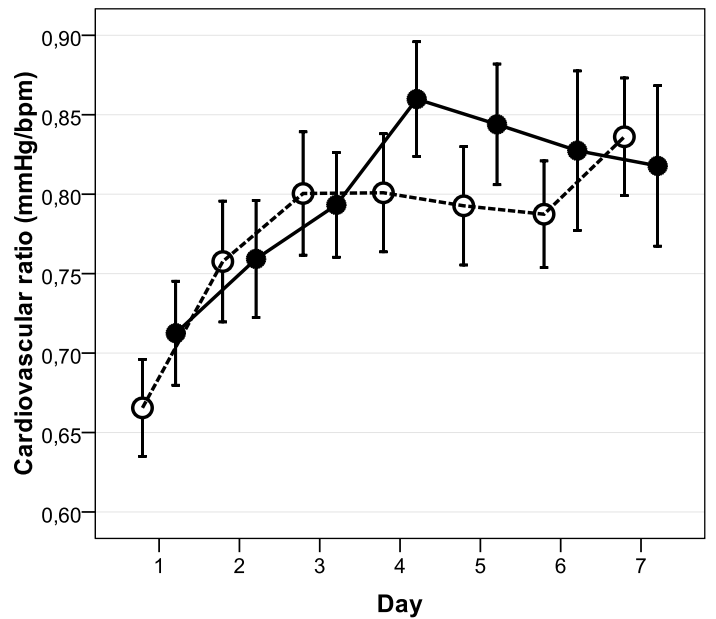

PANEL B: EVLWI

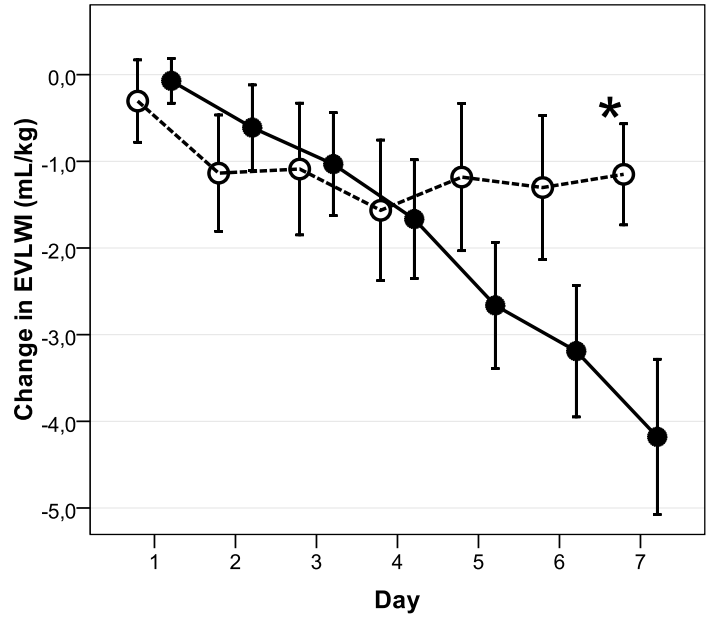

PANEL D: SOFA renal

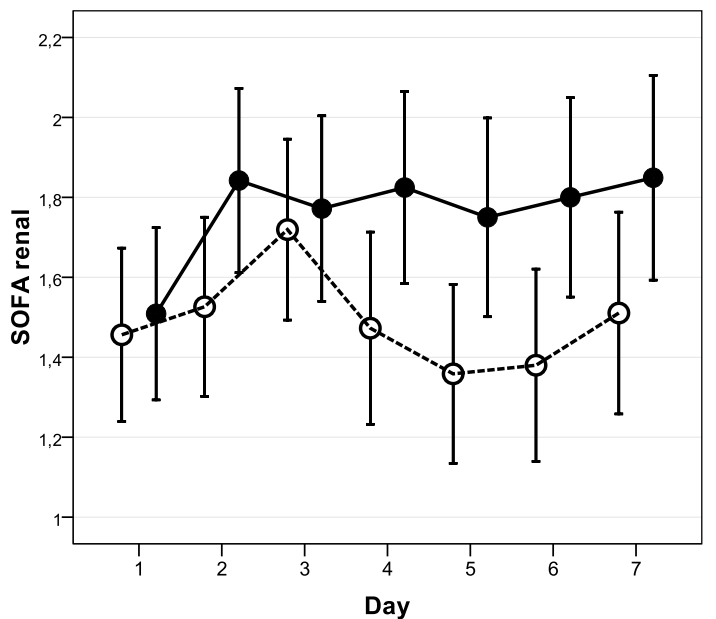

Figure 2 Assessment of respiratory, cardiovascular, and renal functions. Mean \pm standard error for change to baseline in respiratory function (reflected by P/F ratio and EVLWI), cardiovascular function reflected by MAP/heart rate ratio, and renal function as assessed with renal SOFA score during 1 week of PAL-treatment. PAL-treated patients are depicted by a full line and control patients by a dotted line. * $p<0.05$, day-by-day pairwise compared between the PAL group and the control group (one-way ANOVA).

positive fluid balance and development of ALI in patients with sepsis [43]. In view of PAL-treatment as a therapy for capillary leak, beneficial effects of albumin on the microcirculation may be of particular interest, attenuating capillary permeability and pulmonary inflammation [44-47].

PAL-treatment proved to be effective to achieve negative fluid balance. After 1 week, PAL-treated patients

Table 3 Major outcomes

\begin{tabular}{lccc}
\hline & Control group & PAL group & $\boldsymbol{p}$ value \\
\hline Death at day 28 (\%) & 49.1 & 28.1 & 0.034 \\
ICU stay (day) & $37.1 \pm 19.9$ & $23.6 \pm 15$ & 0.006 \\
Hospital stay (day) & $82.5 \pm 57.6$ & $69.8 \pm 66.9$ & 0.475 \\
Vasopressor therapy after 1 week (\%) & 30.6 & 60.8 & 0.003 \\
Duration mechanical ventilation (day) & $25.5 \pm 20.2$ & $14.6 \pm 10.7$ & 0.020 \\
Duration CRRT (day) & $6.2 \pm 8.8$ & $10.0 \pm 3.8$ & 0.437 \\
\hline
\end{tabular}

$\mathrm{ICU}$, intensive care unit; CRRT, continuous renal replacement therapy. 

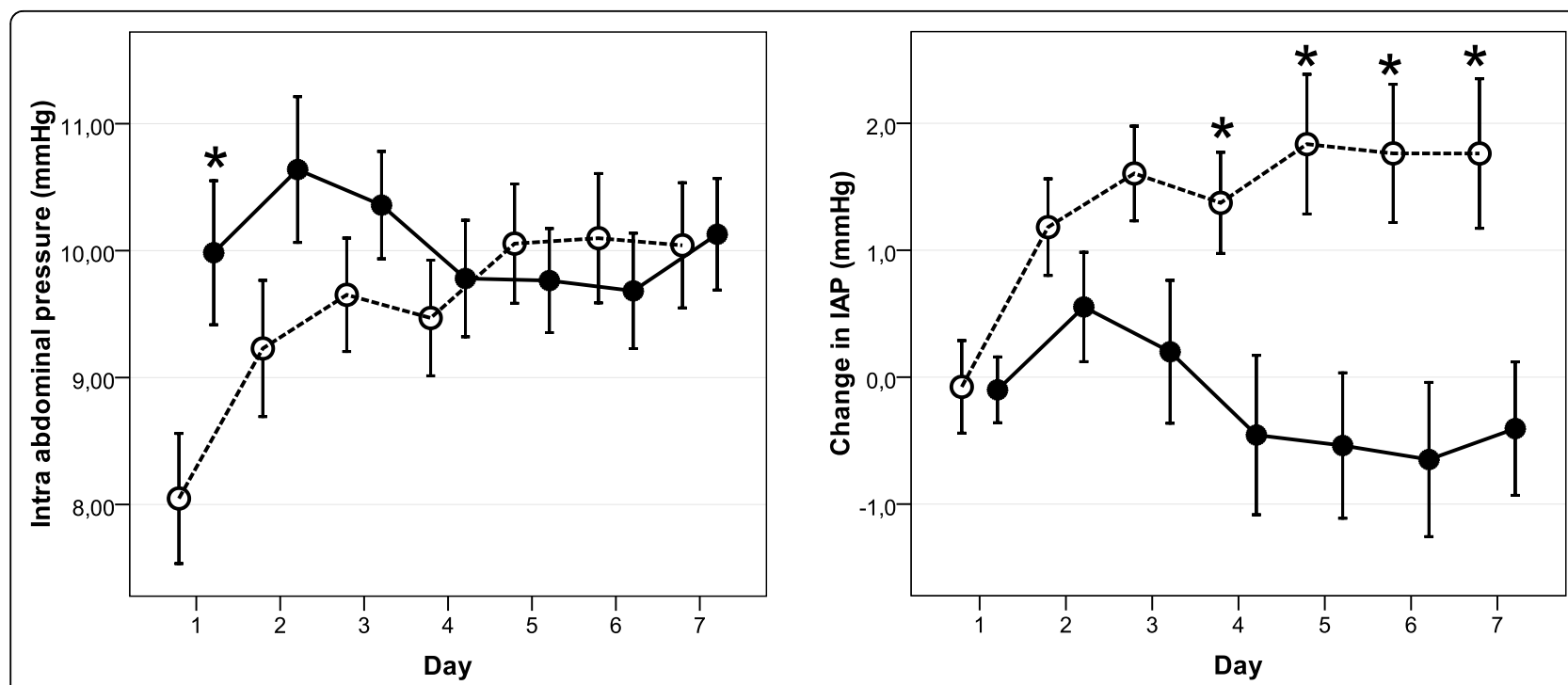

Figure 3 Mean \pm standard error for intra-abdominal pressure during 1 week of PAL-treatment. IAP increases significantly in control patients and remains stable in PAL-treated patients. According to PAL-treatment protocol, PEEP level was titrated to IAP (best PEEP equals IAP) resulting in a mean PEEP of $11.0 \pm 2.8 \mathrm{cmH}_{2} \mathrm{O}$. PAL-treated patients are depicted by a full line and control patients by a dotted line. ${ }^{*} p<0.05$, day-by-day pairwise compared between the PAL group and the control group (one-way ANOVA).

had a net negative cumulative fluid balance while control patients added up to a positive cumulative fluid balance, similar to other cohorts $[12,20]$. In contrast to previous studies, negative fluid balance was pursued as a specific goal. One week of PAL-treatment did not significantly worsen cardiovascular function. Yet, more patients required vasopressor therapy and administered doses were higher. Furthermore, although renal SOFA score on each day was similar in both groups, the PAL group had higher average creatinine for the observed week. In line with previous reports, successful restrictive fluid strategy with PAL-treatment led to improved oxygenation and shortened duration of MV [12,21]. Moreover, PAL-treated patients had a significant greater reduction of EVLWI. This observation possibly reflects improved healing of lung injury, better shock reversal with transition to the flow phase $[15,16,18,19]$. We found PAL-treated patients to have a significant reduction of CLI as a result of restoration of serum albumin.

Overzealous fluid therapy in a setting of capillary leak is an important risk factor for IAH, associated with organ failure and increased mortality [48]. Therefore, a fluid strategy aimed at negative fluid balance and avoiding crystalloid over-resuscitation may play an important
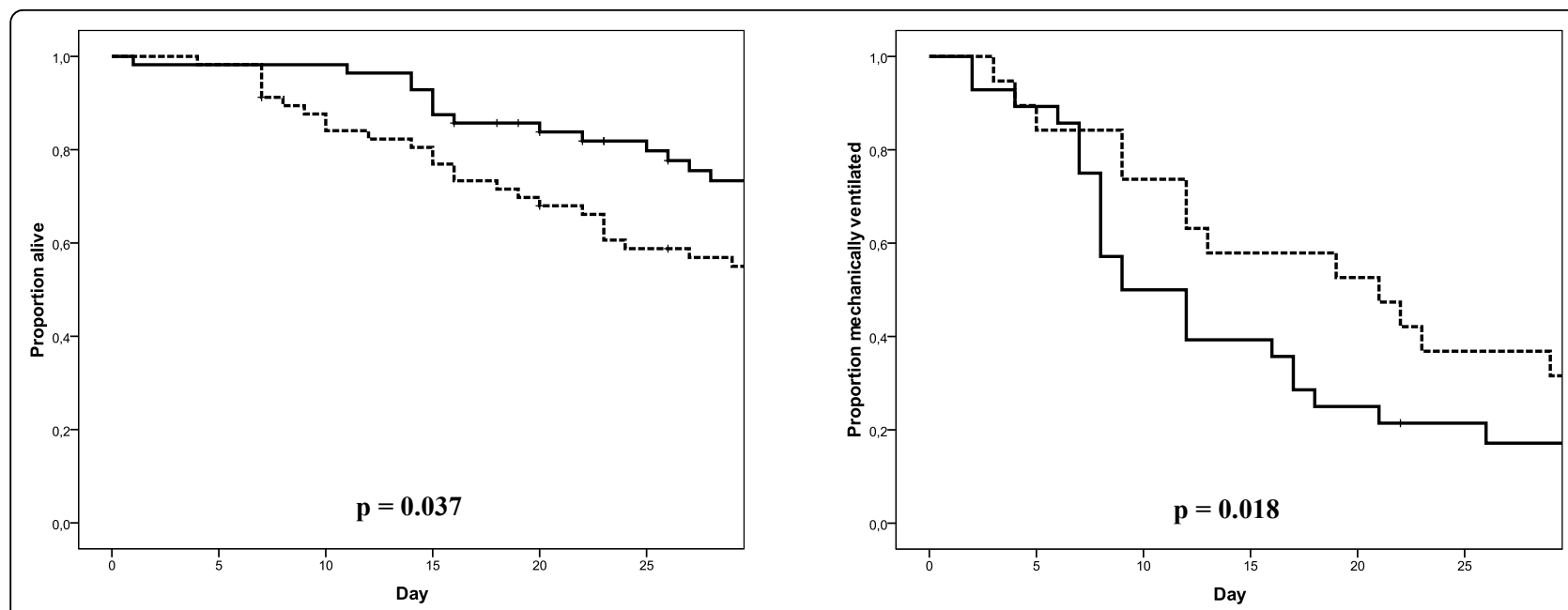

Figure 4 Kaplan-Meier plot for cumulative survival and days on mechanical ventilation. PAL-treated patients are depicted by a full line and control patients by a dotted line. 
role in preventing and even treating IAH [49]. In this context, our observations demonstrated a significant increase of IAP in controls, whereas IAP dropped in PAL-treated patients.

Our study has several important limitations. First, the use of historical controls may raise difficulties to ensure that obtained differences in outcome are related to the studied treatment. Indeed, we cannot deny that continuous evolving standard care has led to better outcomes in patients with acute lung injury [50]. In particular, there are indices that a more protective ventilation (not only higher PEEP as per protocol) was applied in the PAL group since at baseline controls had slightly higher tidal volumes and lower PEEP levels. However, as patients were selected for PAL-treatment based on low oxygenation indices and high EVLWI, they may have had a higher percentage of potentially recruitable lung, requiring higher PEEP levels [35].

Second, the large difference in mortality between the two groups has to be placed in context. Expected mortality in the control group and PAL group was $47 \%$ and $48 \%$, computing a standardized mortality ratio of 1.04 and 1.70, respectively. Apart from the presumed better standard care over time, a selection bias may have been introduced by including only mechanically ventilated patients with thermodilution catheter monitoring. Thus, we selected a specific case mix of severely ill ALI patients prone to exhibit fluid retention, in which attention to fluid balance may be expected to have great potential benefit. In this regard, we note a considerable high cumulative fluid balance after 1 week in controls $(8,027 \mathrm{~mL})$, albeit similar to earlier reports $[12,20]$. Third, since this was an open trial in which fluid therapy decisions were made by the treating physician, the lack of a strict protocol to guide fluid therapy may have introduced bias. Fourth, our database did not supply detailed information on amounts of fluids administrated in the first $6 \mathrm{~h}$. The fluid balance on the day before enrolment was almost $1 \mathrm{~L}$ higher in controls, possibly indicating a more aggressive initial volume replacement. Exact data on the type of fluid used and the rate of hourly ultrafiltration in patients with CRRT were not recorded either.

\section{Conclusion}

PAL-treatment in patients with ALI results in a negative cumulative fluid balance, a reduction of EVLWI and IAP, and improved clinical outcomes. Repercussions on cardiovascular and renal function were limited. Within the concept of dual response to inflammatory injury, we conclude that PAL-treatment could safely and effectively promote the transition to flow phase. Future doubleblinded trials confirming these observations and investigating PAL-treatment in other settings of capillary leak are warranted.

\section{Abbreviations}

ALI: acute lung injury; ANOVA: analysis of variance; APACHE: acute physiology and chronic health evaluation; APP: abdominal perfusion pressure; Cl: cardiac index; CLI: capillary leak index; CO: cardiac output; CRP: C-reactive protein; CRRT: continuous renal replacement therapy; EVLW(I): extravascular lung water (index); GEDV(I): global end diastolic volume (index); GEF: global ejection fraction; IAH: intra-abdominal hypertension; IAP: intraabdominal pressure; ICU: intensive care unit; MAP: mean arterial pressure; MV: mechanical ventilation; PAL-treatment: PEEP + albumin + Lasix (furosemide); PEEP: positive end-expiratory pressure; SAPS: simplified acute physiology score; SOFA: sepsis and organ failure assessment; SW: stroke volume variation; vs: versus.

\section{Acknowledgements}

This article has been published as part of Annals of Intensive Care Volume 2 Supplement 1, 2012: Diagnosis and management of intra-abdominal hypertension and abdominal compartment syndrome. The full contents of the supplement are available online at http://www.annalsofintensivecare. com/supplements/2/S1

The authors are indebted to Ms. Harriet Adamson for her advice and technical assistance with the preparation of this manuscript. The authors also wish to thank the study nurses Ms. Anita Jans and Ms. Kim Serneels (ICU, ZNA Stuivenberg, Antwerp, Belgium) for their fantastic work in keeping the database up-to-date. There was no funding for this study.

The study is supported by the Council of Internal Medicine (head Prof Dr Pierre Zachée, MD, PhD), ZNA Stuivenberg Hospital, who paid for the open access publication fee.

\section{Author details}

'Department of Intensive Care, Ziekenhuis Netwerk Antwerpen, ZNA Stuivenberg, Campus Stuivenberg, Lange Beeldekensstraat 267, 2060, Antwerpen 6, Belgium. ${ }^{2}$ Grady Memorial Hospital, Emory University School of Medicine, Atlanta, GA, USA. ${ }^{3}$ II. Medizinische Klinik, Klinikum Rechts der Isar, Technische Universität München, Munich, Germany.

\section{Authors' contributions}

$C C, I D L, N V R, K S, H D$, and MM planned the study and were responsible for the design, coordination, and drafting the manuscript. GM and $\mathrm{WH}$ participated in the study design and helped to draft the manuscript. CC and MM performed the statistical analysis and helped to draft the manuscript. All authors read and approved the final manuscript.

\section{Competing interests}

GM, WH, and MM are members of the medical advisory board of Pulsion Medical Systems (Munich, Germany), a monitoring company. The other authors declare that they have no competing interests.

Published: 5 July 2012

\section{References}

1. Murphy CV, Schramm GE, Doherty JA, Reichley RM, Gajic O, Afessa B, Micek ST, Kollef MH: The importance of fluid management in acute lung injury secondary to septic shock. Chest 2009, 136(1):102-109.

2. Rivers EP: Fluid-management strategies in acute lung injury - liberal, conservative, or both? The New England journal of medicine 2006, 354(24):2598-2600.

3. Prowle JR, Echeverri JE, Ligabo EV, Ronco C, Bellomo R: Fluid balance and acute kidney injury. Nature reviews 2010, 6(2):107-115.

4. Schrier RW: Fluid administration in critically ill patients with acute kidney injury. Clin J Am Soc Nephrol 2010, 5(4):733-739.

5. Bagshaw SM, Brophy PD, Cruz D, Ronco C: Fluid balance as a biomarker: impact of fluid overload on outcome in critically ill patients with acute kidney injury. Critical care 2008, 12(4):169.

6. Rivers E, Nguyen B, Havstad S, Ressler J, Muzzin A, Knoblich B, Peterson E, Tomlanovich M: Early goal-directed therapy in the treatment of severe 
sepsis and septic shock. The New England journal of medicine 2001, 345(19):1368-1377.

7. Sakr Y, Vincent JL, Reinhart K, Groeneveld J, Michalopoulos A, Sprung CL, Artigas A, Ranieri VM: High tidal volume and positive fluid balance are associated with worse outcome in acute lung injury. Chest 2005, 128(5):3098-3108.

8. Malbrain ML, Cheatham ML, Kirkpatrick A, Sugrue M, Parr M, De Waele J, Balogh Z, Leppaniemi A, Olvera C, Ivatury R, D'Amours S, Wendon J, Hillman $\mathrm{K}$, Johansson $\mathrm{K}$, Kolkman K, Wilmer A: Results from the International Conference of Experts on Intra-abdominal Hypertension and Abdominal Compartment Syndrome. I. Definitions. Intensive care medicine 2006, 32(11):1722-1732.

9. Vincent JL, Sakr Y, Sprung CL, Ranieri VM, Reinhart K, Gerlach H, Moreno R, Carlet J, Le Gall JR, Payen D: Sepsis in European intensive care units: results of the SOAP study. Critical care medicine 2006, 34(2):344-353.

10. Rosenberg AL, Dechert RE, Park PK, Bartlett RH: Review of a large clinical series: association of cumulative fluid balance on outcome in acute lung injury: a retrospective review of the ARDSnet tidal volume study cohort. Journal of intensive care medicine 2009, 24(1):35-46.

11. Payen D, de Pont AC, Sakr Y, Spies C, Reinhart K, Vincent IL: A positive fluid balance is associated with a worse outcome in patients with acute renal failure. Critical care 2008, 12(3):R74.

12. Wiedemann HP, Wheeler AP, Bernard GR, Thompson BT, Hayden $D$, deBoisblanc B, Connors AF Jr, Hite RD, Harabin AL: Comparison of two fluid-management strategies in acute lung injury. The New England journal of medicine 2006, 354(24):2564-2575.

13. Alsous F, Khamiees M, DeGirolamo A, Amoateng-Adjepong Y, Manthous CA Negative fluid balance predicts survival in patients with septic shock: a retrospective pilot study. Chest 2000, 117(6):1749-1754.

14. Berkowitz DM, Danai PA, Eaton S, Moss M, Martin GS: Accurate characterization of extravascular lung water in acute respiratory distress syndrome. Critical care medicine 2008, 36(6):1803-1809.

15. Kuzkov W, Kirov MY, Sovershaev MA, Kuklin VN, Suborov EV, Waerhaug K, Bjertnaes LJ: Extravascular lung water determined with single transpulmonary thermodilution correlates with the severity of sepsisinduced acute lung injury. Critical care medicine 2006, 34(6):1647-1653.

16. Phillips CR, Chesnutt MS, Smith SM: Extravascular lung water in sepsisassociated acute respiratory distress syndrome: indexing with predicted body weight improves correlation with severity of illness and survival. Critical care medicine 2008, 36(1):69-73.

17. Sakka SG, Ruhl CC, Pfeiffer UJ, Beale R, McLuckie A, Reinhart K, MeierHellmann A: Assessment of cardiac preload and extravascular lung water by single transpulmonary thermodilution. Intensive care medicine 2000 26(2):180-187.

18. Sakka SG, Klein M, Reinhart K, Meier-Hellmann A: Prognostic value of extravascular lung water in critically ill patients. Chest 2002, 122(6):2080-2086.

19. Martin GS, Eaton S, Mealer M, Moss M: Extravascular lung water in patients with severe sepsis: a prospective cohort study. Critical care 2005, 9(2):R74-82.

20. Mitchell JP, Schuller D, Calandrino FS, Schuster DP: Improved outcome based on fluid management in critically ill patients requiring pulmonary artery catheterization. The American review of respiratory disease 1992, 145(5):990-998.

21. Martin GS, Moss M, Wheeler AP, Mealer M, Morris JA, Bernard GR: A randomized, controlled trial of furosemide with or without albumin in hypoproteinemic patients with acute lung injury. Critical care medicine 2005, 33(8):1681-1687.

22. Bernard GR, Artigas A, Brigham KL, Carlet J, Falke K, Hudson L, Lamy M, Legall JR, Morris A, Spragg R: The American-European Consensus Conference on ARDS. Definitions, mechanisms, relevant outcomes, and clinical trial coordination. American journal of respiratory and critical care medicine 1994, 149(3 Pt 1):818-824.

23. Deeren DH, Zachee P, Malbrain ML: Granulocyte colony-stimulating factor-induced capillary leak syndrome confirmed by extravascular lung water measurements. Annals of hematology 2005, 84(2):89-94.

24. Le Gall JR, Lemeshow S, Saulnier F: A new Simplified Acute Physiology Score (SAPS II) based on a European/North American multicenter study. Jama 1993, 270(24):2957-2963.

25. Knaus WA, Draper EA, Wagner DP, Zimmerman JE: APACHE II: a severity of disease classification system. Critical care medicine 1985, 13(10):818-829.
26. Vincent JL, de Mendonca A, Cantraine F, Moreno R, Takala J, Suter PM, Sprung CL, Colardyn F, Blecher S: Use of the SOFA score to assess the incidence of organ dysfunction/failure in intensive care units: results of a multicenter, prospective study. Working group on "sepsis-related problems" of the European Society of Intensive Care Medicine. Critical care medicine 1998, 26(11):1793-1800.

27. Malbrain ML: Different techniques to measure intra-abdominal pressure (IAP): time for a critical re-appraisal. Intensive care medicine 2004, 30(3):357-371

28. Cuthbertson DP: Post-shock metabolic response. Lancet 1942, i:433-447.

29. Cerda J, Sheinfeld G, Ronco C: Fluid overload in critically ill patients with acute kidney injury. Blood purification 2010, 29(4):331-338.

30. Elbers PW, Ince C: Mechanisms of critical illness - classifying microcirculatory flow abnormalities in distributive shock. Critical care 2006, 10(4):221.

31. Nieuwenhuijzen GA, Knapen MF, Oyen WJ, Hendriks T, Corstens FH, Goris RJ: Organ damage is preceded by changes in protein extravasation in an experimental model of multiple organ dysfunction syndrome. Shock 1997, 7(2):98-104.

32. Dalfino L, Tullo L, Donadio I, Malcangi V, Brienza N: Intra-abdominal hypertension and acute renal failure in critically ill patients. Intensive care medicine 2008, 34(4):707-713.

33. Simmons RS, Berdine GG, Seidenfeld JJ, Prihoda TJ, Harris GD, Smith JD, Gilbert TJ, Mota E, Johanson WG Jr: Fluid balance and the adult respiratory distress syndrome. The American review of respiratory disease 1987, 135(4):924-929.

34. Malbrain ML, Chiumello D, Pelosi P, Bihari D, Innes R, Ranieri VM, Del Turco M, Wilmer A, Brienza N, Malcangi V, Cohen J, Japiassu A, De Keulenaer BL, Daelemans R, Jacquet L, Laterre PF, Frank G, de Souza P, Cesana B, Gattinoni L: Incidence and prognosis of intraabdominal hypertension in a mixed population of critically ill patients: a multiplecenter epidemiological study. Critical care medicine 2005, 33(2):315-322.

35. Gattinoni L, Caironi P, Cressoni M, Chiumello D, Ranieri VM, Quintel M, Russo S, Patroniti N, Cornejo R, Bugedo G: Lung recruitment in patients with the acute respiratory distress syndrome. The New England journal of medicine 2006, 354(17):1775-1786.

36. Luecke T, Roth H, Herrmann P, Joachim A, Weisser G, Pelosi P, Quintel M: PEEP decreases atelectasis and extravascular lung water but not lung tissue volume in surfactant-washout lung injury. Intensive care medicine 2003, 29(11):2026-2033.

37. Garcia-Delgado M, Touma-Fernandez A, Chamorro-Marin V, Ruiz-Aguilar A, Aguilar-Alonso E, Fernandez-Mondejar E: Alveolar fluid clearance in healthy pigs and influence of positive end-expiratory pressure. Critical care 2010, 14(2):R36.

38. Ruiz-Bailen M, Fernandez-Mondejar E, Hurtado-Ruiz B, Colmenero-Ruiz M, Rivera-Fernandez R, Guerrero-Lopez F, Vazquez-Mata G: Immediate application of positive-end expiratory pressure is more effective than delayed positive-end expiratory pressure to reduce extravascular lung water. Critical care medicine 1999, 27(2):380-384.

39. Chen YM, Yang Y, Qiu HB, Li JQ, Huang YZ, Xu XT: [Effect of protective ventilation and open lung strategy on extravascular lung water in rabbits with acute respiratory distress syndrome]. Zhonghua jie he he hu xi za zhi = Zhonghua jiehe he huxi zazhi = Chinese journal of tuberculosis and respiratory diseases 2005, 28(9):615-618.

40. Malbrain ML, Wilmer A: The polycompartment syndrome: towards an understanding of the interactions between different compartments! Intensive care medicine 2007, 33(11):1869-1872.

41. Starling EH: On the absorption of fluids from the connective tissue spaces. The Journal of physiology 1896, 19(4):312-326.

42. Cribbs SK, Martin GS: Fluid balance and colloid osmotic pressure in acute respiratory failure: optimizing therapy. Expert review of respiratory medicine 2009, 3(6):651-662.

43. Mangialardi RJ, Martin GS, Bernard GR, Wheeler AP, Christman BW, Dupont WD, Higgins SB, Swindell BB: Hypoproteinemia predicts acute respiratory distress syndrome development, weight gain, and death in patients with sepsis. Ibuprofen in Sepsis Study Group. Critical care medicine 2000, 28(9):3137-3145.

44. Lum H, Siflinger-Birnboim A, Blumenstock F, Malik AB: Serum albumin decreases transendothelial permeability to macromolecules. Microvascular research 1991, 42(1):91-102. 
45. Qiao RL, Ying X, Bhattacharya J: Effects of hyperoncotic albumin on endothelial barrier properties of rat lung. The American journal of physiology 1993, 265(1 Pt 2):H198-204.

46. Zhang $\mathrm{H}$, Voglis $\mathrm{S}$, Kim CH, Slutsky AS: Effects of albumin and Ringer's lactate on production of lung cytokines and hydrogen peroxide after resuscitated hemorrhage and endotoxemia in rats. Critical care medicine 2003, 31(5):1515-1522.

47. Powers KA, Kapus A, Khadaroo RG, He R, Marshall JC, Lindsay TF, Rotstein OD: Twenty-five percent albumin prevents lung injury following shock/resuscitation. Critical care medicine 2003, 31(9):2355-2363.

48. Malbrain ML, Chiumello D, Pelosi P, Wilmer A, Brienza N, Malcangi V, Bihari D, Innes R, Cohen J, Singer P, Japiassu A, Kurtop E, De Keulenaer BL, Daelemans R, Del Turco M, Cosimini P, Ranieri M, Jacquet L, Laterre PF, Gattinoni L: Prevalence of intra-abdominal hypertension in critically ill patients: a multicentre epidemiological study. Intensive care medicine 2004, 30(5):822-829

49. Kula R, Szturz P, Sklienka P, Neiser J: Negative fluid balance in patients with abdominal compartment syndrome - case reports. Acta chirurgica Belgica 2008, 108(3):346-349.

50. Milberg JA, Davis DR, Steinberg KP, Hudson LD: Improved survival of patients with acute respiratory distress syndrome (ARDS): 1983-1993. Jama 1995, 273(4):306-309.

doi:10.1186/2110-5820-2-S1-S15

Cite this article as: Cordemans et al: Aiming for a negative fluid balance in patients with acute lung injury and increased intraabdominal pressure: a pilot study looking at the effects of PALtreatment. Annals of Intensive Care 2012 2(Suppl 1):S15.

\section{Submit your manuscript to a SpringerOpen ${ }^{\mathcal{O}}$ journal and benefit from:}

- Convenient online submission

- Rigorous peer review

- Immediate publication on acceptance

- Open access: articles freely available online

- High visibility within the field

- Retaining the copyright to your article

Submit your next manuscript at $\gg$ springeropen.com 